\title{
PENGARUH BAURAN PEMASARAN TERHADAP KEPUTUSAN PEMBELIAN KACANG EDAMAME OLEH KONSUMEN RUMAH TANGGA PADA PASAR SWALAYAN
}

\author{
Nadisha Ghassani1), dan Suyono ${ }^{2)}$ \\ 1,2)Departmen Agribisnis, Fakultas Pertanian Universitas Jenderal Soedirman \\ Jl. DR. Soeparno No. 63, Grendeng, Kec. Purwokerto Utara, Jawa Tengah, Indonesia \\ e-mail: 1)nadisha74@gmail.com
}

(Diterima 27 Maret 2021 / Revisi 3 Mei 2021 / Disetujui 28 Juni 2021)

\begin{abstract}
Edamame is a food product which has a big potential to be developed and marketable, as it is good in terms of taste and nutrition. Several hypermarkets nowadays sell edamame. Therefore, it requires the understanding of what marketing mix affects consumer's purchasing decision towards edamame. This research aimed to find: 1) Consumer's perception of edamame's marketing mix at hypermarkets in East Jakarta, 2) To Evaluate consumer's purchasing decision of edamame at hypermarkets in East Jakarta, 3) The influence of edamame's marketing mix affecting consumer's purchasing decision, 4) The largest influence of edamame's marketing mix which effects consumer's purchasing decision. The method of this research used survey method and the sampling method used was the non-probability sampling method with accidental sampling technique. A total of 100 respondents were calculated using the linear time function formula. The location of this research was chosen purposively i.e., 4 hypermarkets located in East Jakarta. The method of this research is descriptive analysis and path analysis. The results showed that: 1) Edamame's marketing mix have good performance according to the continuum line, 2) Consumer's purchasing decision of edamame have good performance according to the continuum line, 3) The marketing mix simultaneously significantly influenced consumer's purchasing decision of edamame, 4) The promotion variable (X4) gives the biggest influence towards consumer's purchasing decision of edamame. The implication of this research is to increase activities of promotions of edamame.
\end{abstract}

Keywords: consumer, edamame, marketing mix, purchasing decision

\begin{abstract}
ABSTRAK
Kacang edamame merupakan suatu produk pangan yang memiliki peluang besar untuk dikembangkan baik produksi maupun pemasarannya karena produk ini memiliki keunggulan, khususnya dari segi rasa dan gizi. Hanya beberapa pasar swalayan yang menjual kacang edamame, sehingga perlu diketahui variabel bauran pemasaran yang berpengaruh terhadap keputusan konsumen dalam pembelian kacang edamame. Penelitian ini bertujuan untuk: 1) Mengetahui persepsi konsumen terhadap pelaksanaan bauran pemasaran kacang edamame pada pasar swalayan di Jakarta Timur, 2) Mengevaluasi pelaksanaan proses pengambilan keputusan pembelian produk kacang edamame pada pasar swalayan di Jakarta Timur, 3) Mengetahui besarnya pengaruh bauran pemasaran terhadap keputusan pembelian kacang edamame, 4) Mengetahui variabel bauran pemasaran yang paling besar pengaruhnya terhadap keputusan pembelian kacang edamame. Penelitian ini dilakukan pada 4 pasar swalayan jenis hypermarket yang ditentukan secara purposive. Metode penelitian yang digunakan adalah metode survei dengan metode pengambilan sampel menggunakan teknik accidental sampling dengan sampel sebanyak 100 responden. Metode analisis data menggunakan uji validitas dan reliabilitas, analisis deskriptif, uji asumsi klasik, analisis jalur dan uji hipotesis. Hasil penelitian menunujukkan bahwa : 1) Persepsi konsumen terhadap pelaksanaan bauran pemasaran produk kacang edamame pada pasar swalayan di Kota Jakarta Timur berada pada kategori tinggi yang artinya sudah baik; 2) Tahapan yang dilakukan konsumen dalam proses pengambilan keputusan pembelian kacang edamame pada pasar swalayan di Kota Jakarta Timur berada pada kategori tinggi yang artinya sudah baik; 3) Bauran pemasaran secara simultan berpengaruh positif dan signifikan terhadap keputusan pembelian kacang edamame; 4) Variabel bauran pemasaran yang paling berpengaruh terhadap keputusan pembelian kacang edamame adalah variabel promosi (X4). Implikasi penelitian ini adalah meningkatkan kegiatan dan penyebarluasan informasi promosi untuk meningkatkan frekuensi pembelian kacang edamame.
\end{abstract}

Kata kunci: bauran pemasaran, edamame, keputusan pembelian, konsumen 


\section{PENDAHULUAN}

Indonesia merupakan negara agraris yang kaya akan sumber daya alam, terutama hasil pertanian seperti beras, jagung dan kedelai. Kedelai merupakan produk yang bernilai ekonomi tinggi. Kedelai merupakan salah satu tanaman pangan yang memiliki peranan penting di Indonesia dan permintaan kedelai di dalam negeri semakin meningkat setiap tahunnya seiring dengan pertambahan jumlah penduduk. Permintaan baru mulai bermunculan di Indonesia, salah satu jenis kedelai yang ditanam adalah edamame. Legum ini dipanen dan dimakan saat belum matang sempurna (Coolong, 2009).

Kedelai hijau dan kedelai kuning memiliki spesies yang sama: Glycine max (L.) Merrill, tetapi edamame memiliki rasa yang lebih manis, aroma yang lebih kaya, tekstur yang lebih halus, biji yang lebih besar daripada kedelai kuning, dan nutrisi yang lebih kaya dan mudah dicerna oleh tubuh dibandingkan kedelai kuning (Rackis, 1978). Konovsky (2004) menyatakan bahwa edamame cocok ditanam di Indonesia karena kedelai hijau dapat tumbuh di iklim tropis dan subtropis dengan suhu yang cukup panas dan curah hujan yang relatif tinggi. Waktu panen edamame relatif singkat, 63 sampai 68 hari setelah tanam. Kacang edamame bahkan kurang populer di Indonesia karena sebagian besar diekspor ke Jepang dan Amerika Serikat. Medianti (2019) menyatakan bahwa Kementerian Pertanian terus berupaya untuk meningkatkan produk pertanian Indonesia menuju pasar dunia. Pada tahun 2019, Indonesia melakukan ekspor edamame sebanyak 115 ton ke Jepang yang merupakan konsumen dan pasar utama edamame.

Berdasarkan penelitian terdahulu dalam mengetahui pengaruh faktor budaya terhadap keputusan pembelian kacang edamame di Medan, Pebriani (2019) menyatakan bahwa masyarakat Indonesia khususnya yang merupakan etnis Tionghoa memiliki kebiasaan dari leluhur untuk mengkonsumsi kacang edamame karena sudah dianggap sebagai makanan yang memiliki manfaat yang baik, penyajian yang mudah serta sudah menjadi bagian dari gaya hidup sehat masyarakat tersebut dalam mengkonsumsi kacang edamame. Kacang edamame cukup mudah untuk diterima masyarakat karena informasi dan rekomendasi mengenai kacang edamame diperoleh dari teman atau kerabat dekat (Pebriani, 2019). Oleh karena itu, peneliti ingin mengetahui apakah ada pengaruh lain selain faktor budaya seperti bauran pemasaran yang mempengaruhi konsumen melakukan pembelian, khususnya di Ibu Kota yang merupakan salah satu tempat perputaran informasi dan globalisasi di Indonesia. Kacang edamame yang diteliti dalam penelitian ini merupakan kacang edamame segar (mentah).

Bauran pemasaran adalah kombinasi variabel dan aktivitas yang membentuk suatu sistem pemasaran. Variabel-variabel dalam bauran pemasaran dapat dikendalikan oleh perusahaan untuk mempengaruhi respon pembeli atau konsumen (Fitriyono \& Khuzaini, 2014). Konsep bauran pemasaran merupakan salah satu faktor penting bagi pelaku bisnis dalam merancang strategi pemasaran yang efektif, dan diharapkan dapat digunakan oleh konsumen sebagai acuan dalam mengambil keputusan untuk membeli produk.

Menurut Kotler \& Armstrong (2008), keputusan pembelian merupakan bagian dari proses pengambilan keputusan pembeli di mana konsumen secara nyata membeli produk. Pengambilan keputusan merupakan kegiatan individu yang berhubungan langsung dengan pembelian dan penggunaan produk yang ditawarkan. Tipe konsumen menurut Tjiptono (2004) sebagai berikut: 1) Konsumen akhir atau konsumen rumah tangga, yaitu konsumen yang melakukan pembelian untuk kepentingan diri sendiri, keluarga, atau keperluan lain, tanpa bermaksud untuk memperjualbelikan produk; dan 2) Konsumen bisnis adalah jenis konsumen yang melakukan pembelian untuk keperluan pemrosesan lebih lanjut yang kemudian dijual kepada pihak lain.

Konsumen rumah tangga dijadikan objek dalam penelitian ini dengan tujuan untuk mengetahui persepsi konsumen mengenai kacang edamame serta perilaku konsumen saat melakukan keputusan pembelian produk. Konsumen rumah tangga dianggap lebih berpengalaman karena telah mengkonsumsi produk. Konsumen rumah tangga yang sudah mengkonsumsi tentunya mengetahui kegunaan produk, harga produk, tempat pembelian produk, promosi yang ditawarkan dan besarnya pengaruh setiap komponen 
tersebut sehingga melakukan keputusan pembelian produk. Untuk mencapai keputusan pembelian, konsumen harus mengenali masalah yang sedang dihadapi, kemudian mencari informasi terkait produk atau jasa yang dapat menyelesaikan permasalahannya, mengevaluasi alternatif yang tersedia, dan akhirnya melakukan keputusan untuk melakukan pembelian produk atau penggunaan jasa untuk menyelesaikan masalah tersebut (Hurriyati, 2005).

Kota Jakarta Timur merupakan kotamadya terbesar di Provinsi DKI Jakarta dengan luas wilayah 188,03 km², dan terdiri atas 10 kecamatan dan 65 kelurahan. Jumlah penduduk di wilayah Kota Jakarta Timur per tahun 2019 sebesar 2,937,859 jiwa (BPS Kota Jakarta Timur, 2020). Jumlah pasar swalayan di Kota Jakarta Timur sebanyak 33 pasar swalayan (Dinas Kelautan, Pertanian dan Ketahanan Pangan Provinsi DKI Jakarta, 2015). Namun, tidak semua hypermarket di Jakarta Timur terdapat menjual produk kacang edamame. Pasar swalayan yang dipilih dalam penelitian ini merupakan pasar swalayan dengan tipe hypermarket dengan pertimbangan berdasarkan penelitian terdahulu oleh Afifah et al. (2018), bahwa hypermarket memiliki ketersediaan produk lebih kontinyu dan beragam jika dibandingkan dengan pasar swalayan jenis lain.

Berdasarkan uraian di atas, tujuan dari penelitian ini adalah untuk: 1) Mengetahui persepsi konsumen terhadap pelaksanaan bauran pemasaran produk kacang edamame pada pasar swalayan di Kota Jakarta Timur; 2) Mengevaluasi tahapan-tahapan yang dilakukan konsumen dalam proses pengambilan keputusan kacang edamame pada pasar swalayan di Kota Jakarta Timur; 3) Mengetahui besarnya pengaruh bauran pemasaran terhadap keputusan pembelian kacang edamame pada pasar swalayan di Kota Jakarta Timur; 4) Mengetahui variabel bauran pemasaran yang paling berpengaruh terhadap keputusan pembelian kacang edamame pada pasar swalayan di Kota Jakarta Timur.

\section{METODE}

\section{TEMPAT DAN WAKTU}

Penentuan tempat penelitian dilakukan secara purposive. Penelitian dilakukan di pasar swalayan jenis hypermarket. Penelitian ini dilakukan di 4 hypermarket yang dapat mewakili konsumen di Jakarta Timur. Pembagian wilayah dan pasar swalayan yaitu: 1)Utara: AEON Hypermart JGC, Kecamatan Cakung; 2) Timur: Transmart Carrefour Buaran, Kecamatan Duren Sawit, 3) Selatan: Lotte Hypermart, Kecamatan Pasar Rebo, dan 4) Barat: Carrefour Lippo Mall, Kecamatan Kramat Jati. Penelitian telah dilaksanakan pada bulan September sampai Oktober 2020.

\section{PENGUMPULAN DATA}

Metode pengambilan sampel yang digunakan dalam penelitian ini adalah non probability sampling. Non probability sampling merupakan teknik sampling yang tidak memberi peluang atau kesempatan yang sama bagi setiap unsur atau anggota populasi untuk dipilih menjadi sampel (Sugiyono, 2018). Metode yang digunakan untuk penentuan sampel adalah accidental sampling. Menurut Sugiyono (2018), accidental sampling merupakan teknik penentuan sampel berdasarkan kebetulan, yaitu siapa saja yang secara kebetulan atau insidental bertemu dengan peneliti dapat digunakan sebagai sampel, bila dipandang orang yang ditemui itu cocok sebagai sumber sebagai sumber data.

Sasaran penelitian ini adalah konsumen yang membeli produk kacang edamame minimal 500gr. Kriteria responden adalah konsumen berusia minimal 17 tahun serta pernah membeli dan mengkonsumsi kacang edamame minimal dua kali. Menurut Abidin et al. (2017) pengambilan sampel berdasarkan linear time function dapat dilakukan bila jumlah populasinya tidak dapat diketahui secara pasti. Rumus dari metode linear time function menurut Sari (1993) sebagai berikut:

$$
n=\frac{T-t_{0}}{t_{1}}=\frac{720-180}{6}=90 \text { responden (minimal) }
$$

Keterangan:

$\mathrm{n}$ : Jumlah sampel

$\mathrm{T}$ : Waktu yang tersedia untuk penelitian

$t_{o}$ : Waktu tetap yang tidak tergantung pada ukuran sampel

$\mathrm{t}_{1}$ : Waktu yang digunakan setiap sampel unit 
Berdasarkan rumus ini, waktu yang tersedia untuk penelitian adalah sebesar 30 hari atau 720 jam. Waktu tetap yang diberikan oleh hypermarket untuk pengambilan sampel adalah 6 jam per hari. Waktu yang dianggap ramai pengunjung adalah pada pukul 13:00 WIB sampai dengan pukul 19:00 WIB. Waktu yang digunakan untuk setiap unit sampel adalah sebesar 0,2 jam atau sekitar 10 sampai 15 menit. Persyaratan minimal jumlah sampel yang digunakan dalam survei ini adalah 90 orang, tetapi jumlah responden yang diambil peneliti adalah sebesar 100 orang. Alokasi pembagian responden dilakukan dengan teknik sampling kuota. Jumlah responden akan dibagi sesuai dengan jumlah pasar swalayan yang telah ditentukan yaitu 4 lokasi sehingga jumlah responden pada masingmasing lokasi penelitian yaitu 25 orang responden.

\section{METODE ANALISIS DATA}

\section{Uji Validitas dan Reliabilitas}

Uji validitas dan uji reliabilitas merupakan uji pra survei yang dilakukan untuk menguji kuesioner. Kriteria pengujian uji validitas pada butir pertanyaan dianggap sesuai jika nilai Pearson Product Moment (koefisien korelasi) berharga positif pada taraf signifikan sebesar $5 \%$ $(0,05)$ dan nilai $r$ hitung $>r$ tabel $(0,361)$, maka elemen pertanyaan dapat dinyatakan valid.

Rumus Alpha Cronbach digunakan untuk mengimplementasikan standar pengujian uji reliabilitas. Untuk menentukan apakah alat tersebut reliabel, digunakan nilai batasan yaitu Cronbach's Alpha > 0,7 (Priyanto, 2012).

Hasil uji validitas menunjukkan bahwa semua 35 butir pertanyaan dinyatakan valid. Berdasarkan hasil uji reliabilitas dapat disimpulkan bahwa variabel bebas $(\mathrm{X})$ dan variabel terikat $(\mathrm{Y})$ memiliki nilai $\mathrm{r}_{\text {hitung }}$ lebih besar dari Alpha Cronbach (0,7), maka semua variabel dalam penelitian ini dapat dinyatakan reliabel. Berdasarkan hasil uji validitas dan reliabilitas, dapat disimpulkan bahwa alat pengumpul data dapat digunakan sebagai pengukuran dalam penelitian ini.

\section{Analisis Deskriptif}

Analisis deskriptif digunakan untuk memahami tujuan pertama dan kedua penelitian ini : mengetahui deskripsi bauran pemasaran produk kacang edamame dan keputusan pembelian produk kacang edamame oleh konsumen rumah tangga pada pasar swalayan di Kota Jakarta Timur. Menurut Sugiyono (2018), analisis deskripsi dapat disimpulkan berdasarkan data dari rekapitulasi penilaian skoring penelitian, di mana nilai skor dibandingkan dengan skor terendah yang didapat melalui perhitungan skor ideal (kriterium) dan skor terkecil. Daerah kontinum yang menunjukkan wilayah ideal dari setiap variabel yang diteliti dapat diketahui melalui skor standar tersebut.

\section{Uji Asumsi Klasik \\ 1) Uji Multikolinieritas}

Uji multikolinearitas bertujuan untuk menguji apakah terdapat korelasi yang signifikan antara variabel bebas dalam suatu model regresi. Model regresi yang baik menegaskan bahwa tidak ada korelasi antara variabel independen (Ghozali, 2009). VIF (Variance Inflation Faktor) digunakan untuk mengetahui ada tidaknya multikolinearitas. Apabila nilai VIF $<10$ dan nilai Tolerance $>0,1$ (10\%), model regresi tidak ada multikolinearitas. Hasil uji multikolinieritas adalah:

Tabel 1. Hasil Uji Multikolinearitas

\begin{tabular}{lcc}
\hline \multirow{2}{*}{\multicolumn{1}{c}{ Model }} & \multicolumn{2}{c}{ Collinearity Statistics } \\
\cline { 2 - 3 } & Tolerance & VIF \\
\hline (Constant) & & \\
Produk & .614 & 1.630 \\
Harga & .686 & 1.457 \\
Tempat & .507 & 1.973 \\
Promosi & .598 & 1.671 \\
Bukti Fisik & .518 & 1.932 \\
\hline
\end{tabular}

a. Dependent Variable: Keputusan Pembelian

Sumber: Hasil Pengolahan Data Primer dengan SPSS, 2020.

Berdasarkan output pada Tabel 1, dapat diketahui bahwa nilai Tolerance semua variabel $\mathrm{X}$ bernilai lebih dari 0,1 (Tolerance $>0,1$ ) dan nilai VIF semua variabel independen bernilai lebih dari 10 (VIF <10). Dengan demikian dapat disimpulkan bahwa tidak ada gejala Multikolinearitas. 


\section{2) Uji Heteroskedastisitas}

Uji heteroskedastisitas adalah varian residual yang tidak sama pada semua pengamatan model regresi. Regresi yang baik seharusnya tidak terjadi heteroskedastisitas (Priyatno, 2012). Hasil uji heteroskastisitas pada Tabel 2 menunjukkan bahwa, nilai signifikansi untuk semua variabel independen memiliki nilai di atas 0,05. Hasil tersebut dapat menyimpulkan bahwa tidak terjadi heteroskedastisitas.

Tabel 2. Hasil Uji Heteroskedastisitas

\begin{tabular}{lrrrrr}
\hline \multirow{2}{*}{ Model } & \multicolumn{2}{c}{$\begin{array}{c}\text { Un- } \\
\text { standardized } \\
\text { Coefficients }\end{array}$} & $\begin{array}{c}\text { Standardized } \\
\text { Coefficients }\end{array}$ & & \\
\cline { 2 - 4 } & B & $\begin{array}{c}\text { Std. } \\
\text { Error }\end{array}$ & Beta & t & Sig. \\
\hline Constant & 1.037 & .954 & & 1.087 & .280 \\
Produk & -.016 & .031 & -.064 & -.503 & .616 \\
Harga & -.055 & .048 & -.140 & -1.159 & .249 \\
Tempat & -.035 & .029 & -.173 & -1.225 & .224 \\
Promosi & .022 & .049 & .058 & .445 & .657 \\
Bukti Fisik & .093 & .049 & .264 & 1.895 & .061 \\
\hline a. Dependent Variable: ABRESID & & & \\
Sumber: Hasil Pengolahan Data Primer dengan SPSS, 2020.
\end{tabular}

\section{3) Uji Normalitas}

Uji Normalitas digunakan untuk menguji apakah variabel terikat dan variabel bebas memiliki distribusi normal atau tidak dalam suatu model regresi (Umar, 2010). Berdasarkan hasil Uji Normalitas One-Sample Kolmogorov-Smirnov Test, diperoleh nilai Asymp.Sig. sebesar 0,851 dan nilai Kolmogorv Smirnov Z sebesar 0,610 yang merupakan $>0,05$, maka dapat disimpulkan data berdistribusi normal. Hasil tersebut ditunjukkan pada Tabel 3.

Tabel 3. Hasil Uji Normalitas One-Sample Kolmogorov-Smirnov Test

\begin{tabular}{llr}
\hline & \multicolumn{2}{c}{$\begin{array}{c}\text { Standardized } \\
\text { Residual }\end{array}$} \\
\hline $\mathrm{N}$ & Mean & 100 \\
Normal Parameters ${ }^{\mathrm{a}, \mathrm{b}}$ & Std. & $0 \mathrm{E}-7$ \\
& Deviation & .97442031 \\
& Absolute & .016 \\
Most Extreme Differences & Positive & .050 \\
& Negative & -.061 \\
& & .610 \\
Kolmogorov-Smirnov Z & .851 \\
Asymp. Sig. (2-tailed) & & \\
\hline a. Test distribution is Normal. & \\
b. Calculated from data. & & \\
Sumber: Hasil Pengolahan Data Primer dengan SPSS, 20
\end{tabular}

\section{Analisis Jalur}

Analisis jalur digunakan untuk menjawab tujuan penelitian ketiga: mengetahui pengaruh bauran pemasaran kacang edamame terhadap keputusan pembelian konsumen. Besarnya pengaruh dari suatu variabel bebas ke variabel terikat disebut koefisien jalur (path coefficient) dan diberi simbol $\rho_{y x i}$.

Koefisien determinasi adalah besarnya pengaruh variabel eksogen terhadap variabel endogen yang dapat dijelaskan oleh model persamaan jalur. Nilai $r^{2}$ persamaan jalur yang mendekati $100 \%$ menunjukkan bahwa semakin banyak keragaman variabel eksogen terhadap variabel endogen seperti pada persamaan struktural:

\section{$Y=\rho_{Y X 1} X 1+\rho_{Y X 2} X 2+\rho_{Y X 3} X 3+\rho_{Y X} X 4+\rho_{Y X 5} X 5+\varepsilon$}

Keterangan :

Q Q $_{\mathrm{yxi}}=$ Koefisien jalur variabel $\mathrm{x}$ terhadap $\mathrm{y}$

$\varepsilon \quad=$ variabel residu

\section{Uji Hipotesis}

Hipotesis yang sudah dirumuskan kemudian dilakukan pengujian. Uji $F$ dan Uji $t$ membuktikan Ho atau Ha yang akan diterima (Sarwono, 2006).

\section{1) Uji F}

Uji $\mathrm{F}$ adalah untuk mengetahui pengaruh koefisien regresi yang digunakan secara bersamasama apakah secara nyata atau tidak berpengaruh terhadap variabel terikat (Sarwoko, 2005). Adapun formulanya:

$$
F=\frac{R^{2}(N-k-1)}{k\left(1-R^{2}\right)}
$$

Keterangan:

$\mathrm{F}=$ nilai $\mathrm{F}$ yang akan dihitung

$\mathrm{R}^{2}=$ Koefisien Determinasi

$\mathrm{k}=$ jumlah variabel independen

$\mathrm{n}$ = jumlah sampel

Hipotesis yang digunakan yaitu:

Ho : variabel produk, harga, tempat, promosi dan bukti fisik secara bersama-sama tidak memiliki pengaruh yang signifikan terhadap keputusan pembelian kacang edamame.

Ha : minimal salah satu variabel bebas memiliki keputusan pembelian kacang edamame. pengaruh yang signifikan terhadap 
Hipotesis tersebut apabila dinyatakan secara statistik sebagai berikut:

Ho : ? $?_{\mathrm{yx} 1}=?_{\mathrm{yx} 2}=?_{\mathrm{yx} 3}=?_{\mathrm{yx} 4}=?_{\mathrm{yx} 5}=0$, yaitu tidak terdapat pengaruh variabel eksogen terhadap variabel endogen.

Ha : ? yxi $_{\text {y }}>0,(\mathrm{i}=1,2,3,4,5)$, yaitu minimal salah satu variabel eksogen memiliki pengaruh yang signifikan terhadap variabel endogen.

Dasar Pengambilan Keputusan:

1. Apabila $F_{\text {hitung }}>F_{\text {tabel }}$ pada tingkat signifikansi $5 \%(\alpha=0,05)$, maka Ho ditolak atau $\mathrm{Ha}$ diterima.

2. Apabila $F_{\text {hitung }} \leq \mathrm{F}_{\text {tabel }}$ pada tingkat signifikansi $5 \%(\alpha=0,05)$, maka Ho diterima atau $\mathrm{Ha}$ ditolak.

\section{2) Uji t}

Uji t digunakan untuk menguji pengaruh koefisien regresi yang digunakan secara parsial berpengaruh nyata atau tidak terhadap variabel terikat (Sarwoko, 2005). Pengujian sub hipotesis sebagai berikut:

1. Variabel produk $\left(\mathrm{X}_{1}\right)$ memiliki pengaruh yang positif dan signifikan terhadap keputusan pembelian kacang edamame.

2. Variabel harga $\left(X_{2}\right)$ memiliki pengaruh yang positif dan signifikan terhadap keputusan pembelian kacang edamame.

3. Variabel tempat $\left(\mathrm{X}_{3}\right)$ memiliki pengaruh yang positif dan signifikan terhadap keputusan pembelian kacang edamame.

4. Variabel promosi $\left(\mathrm{X}_{4}\right)$ memiliki pengaruh yang positif dan signifikan terhadap keputusan pembelian kacang edamame.

5. Variabel bukti fisik $\left(\mathrm{X}_{5}\right)$ memiliki pengaruh yang positif dan signifikan terhadap keputusan pembelian kacang edamame.

Hipotesis secara statistik :

Ho : ? ?XX $_{\mathrm{Xi}}=0$

$\mathrm{Ha}:$ ? $?_{\mathrm{YXi}}>0$

Dasar pengambilan keputusan:

1. Apabila thitung $>t_{\text {tabel }}$ pada tingkat signifikansi $5 \%(\alpha=0,05)$, maka Ho ditolak atau $\mathrm{Ha}$ diterima.
2. Apabila $t_{\text {hitung }} \leq t_{\text {tabel }}$ pada tingkat signifikansi $5 \%(\alpha=0,05)$, maka Ho diterima atau Ha ditolak.

\section{HASIL DAN PEMBAHASAN}

\section{KARASTERISTIK RESPONDEN}

Responden dalam penelitian ini adalah konsumen yang membeli kacang edamame. Jumlah konsumen yang diteliti dalam penelitian ini sebanyak 100 orang dan jumlah pasar swalayan yang dijadikan lokasi dalam penelitian untuk mewakili Jakarta Timur sebanyak 4 pasar swalayan. Responden yang diambil dari masingmasing pasar swalayan sebanyak 25 orang. Karakteristik responden dapat dijelaskan sebagai berikut:

Tabel 4. Karakteristik Responden Berdasarkan Jenis Kelamin

\begin{tabular}{lcc}
\hline Jenis Kelamin & Jumlah & Persentase (\%) \\
\hline Laki-laki & 37 & 37 \\
Perempuan & 63 & 63 \\
\hline Jumlah & $\mathbf{1 0 0}$ & $\mathbf{1 0 0}$ \\
\hline
\end{tabular}

Sumber: Hasil Pengolahan Data Primer dengan SPSS, 2020.

Berdasarkan Tabel 4, responden yang merupakan konsumen laki - laki adalah $37 \%$ dan konsumen perempuan adalah $63 \%$. Jumlah responden yang dominan dalam melakukan keputusan pembelian kacang edamame berdasarkan tabel tersebut adalah konsumen perempuan. Hal ini selaras dengan pernyataan dari Utami (2013) bahwa perempuan pada umumnya mempunyai peran yang besar sebagai pengambil keputusan dalam melakukan kegiatan belanja kebutuhan sehari-hari. Selanjutnya karakteristik responden berdasarkan kelompok umur ditunjukkan pada Tabel 5

Tabel 5. Karakteristik Responden Berdasarkan Kelompok Umur Produktif Dan Non-Produktif

\begin{tabular}{lcc}
\hline Umur & Jumlah & Persentase (\%) \\
\hline $0-14$ & 0 & 0 \\
$15-64$ & 99 & 99 \\
$\geq 65$ & 1 & 1 \\
\hline Jumlah & $\mathbf{1 0 0}$ & $\mathbf{1 0 0}$ \\
\hline Sumber: Hasil Pengolahan Data Primer dengan SPSS, 2020.
\end{tabular}


Berdasarkan hasil penelitian, sebagian besar konsumen kacang edamame merupakan konsumen pada kelompok umur produktif (15 64 tahun) yaitu sebesar 99\%, dan 1\% lainnya merupakan konsumen pada kelompok umur tidak produktif (di atas 65 tahun). Hal ini berkorelasi dengan hasil sensus penduduk DKI Jakarta tahun 2020, yang menyatakan bahwa komposisi penduduk menurut kelompok umur produktif lebih besar dari kelompok umur non-produktif di Jakarta Timur. Kelompok umur produktif (15-64 tahun) di Jakarta Timur adalah sebesar 71,79\% dan kelompok umur sudah tidak produktif (65 tahun ke atas) adalah sebesar 4,72\%.

Pendidikan merupakan hal penting yang dapat menunjang kualitas sumber daya manusia. Menurut Utami (2013), tingkat pendidikan seseorang dapat mempengaruhi jenis pekerjaan, pendapatan serta pola konsumsi seseorang. Berdasarkan hasil penelitian, dapat diketahui bahwa karakteristik responden berdasarkan pendidikan terakhir dengan persentase tertinggi merupakan responden yang telah menempuh pendidikan terakhir sarjana sebesar 59\%. Responden dengan pendidikan terakhir SMA sebesar 20\%, Diploma 15\% dan Pasca Sarjana sebesar 6\%. Hal ini sejalan dengan pernyataan Sumarwan (2002), bahwa tingkat pendidikan menentukan seseorang dalam menerima pengetahuan dan informasi sehingga konsumen yang memiliki pendidikan yang baik akan lebih responsif terhadap informasi yang dapat mempengaruhi dalam pemilihan suatu produk. Informasi mengenai manfaat serta karakteristik produk dibutuhkan oleh konsumen untuk memberi keyakinan kepada konsumen agar melakukan pembelian. Selanjutnya karakteristik responden berdasarkan jenis pekerjaan adalah:

Tabel 6. Karakteristik Responden Berdasarkan Pekerjaan

\begin{tabular}{lcc}
\hline Pekerjaan & Jumlah & Persentase (\%) \\
\hline Ibu Rumah Tangga & 20 & 20 \\
Pegawai Swasta & 46 & 46 \\
PNS & 13 & 13 \\
Wiraswasta & 18 & 18 \\
Pelajar/Mahasiswa & 3 & 3 \\
\hline Jumlah & $\mathbf{1 0 0}$ & $\mathbf{1 0 0}$ \\
\hline Sumber: Hasil Pengolahan Data Primer dengan SPSS, 2020.
\end{tabular}

wa sebagian besar responden memiliki pekerjaan sebagai pegawai swasta sebesar 46\%, PNS sebesar $13 \%$ dan wiraswasta sebesar 18\%. Hal ini menunjukkan bahwa konsumen kacang edamame merupakan konsumen yang produktif dan sedang bekerja, sehingga pertukaran informasi mengenai kacang edamame dapat terjadi antar rekan kerja.

Tabel 7. Penghasilan per Bulan Responden Berdasarkan UMP DKI Jakarta

\begin{tabular}{lcc}
\hline $\begin{array}{c}\text { Penghasilan } \\
\text { (Rp/bulan) }\end{array}$ & Jumlah & $\begin{array}{c}\text { Persentase } \\
\text { (\%) }\end{array}$ \\
\hline$<=$ Rp4.416.186 & 20 & 20 \\
$>$ Rp4.416.186 & 80 & 80 \\
\hline Jumlah & $\mathbf{1 0 0}$ & $\mathbf{1 0 0}$ \\
\hline Sumber: Hasil Pengolahan Data Primer dengan SPSS, 2020
\end{tabular}

Pendapatan rumah tangga memiliki dampak besar pada tingkat konsumsi. Secara umum, semakin tinggi tingkat pendapatan, semakin tinggi tingkat konsumsi. Peningkatan pendapatan juga dapat menciptakan gaya hidup yang lebih konsumtif, dengan meningkatkan kemampuan rumah tangga untuk membeli kebutuhan konsumen yang berbeda atau dengan menuntut kualitas hidup yang lebih baik (Wahab, 2012).

Tabel 8. Karakteristik Responden Berdasarkan Domisili

\begin{tabular}{lcr}
\hline Domisili & Jumlah & Persentase (\%) \\
\hline Luar Jakarta Timur & 6 & 6 \\
Jakarta Timur & 94 & 94 \\
\hline Jumlah & $\mathbf{1 0 0}$ & $\mathbf{1 0 0}$ \\
\hline Sumber: Hasil Pengolahan Data Primer dengan SPSS, 2020.
\end{tabular}

Berdasarkan Tabel 8, dapat diketahui bahwa sebesar 94\% konsumen kacang edamame berdomisili di Jakarta Timur. Hasil penelitian menunjukkan bahwa penyebaran konsumen di wilayah Jakarta Timur tersebar dengan rata. Jumlah responden yang berdomisili di luar Kota Jakarta Timur ada 6\% yaitu responden dari Kabupaten Bekasi. Hal ini dapat terjadi karena wilayah Jakarta Timur berbatasan di sebelah timur dengan Kabupaten Bekasi.

\section{PERSEPSI KONSUMEN MENGENAI BAURAN PEMASARAN KACANG EDAMAME}

Tanggapan konsumen terhadap bauran pemasaran kacang edamame dan rekapitulasi 
hasil skoring pelaksanaan bauran pemasaran dan keputusan pembelian sebagai berikut:

\section{1) Produk (X1)}

Produk merupakan titik fokus kegiatan pemasaran, sehingga membutuhkan keunggulan untuk menarik konsumen untuk membeli produk. Tanggapan responden mengenai warna kacang edamame yang bagus ditunjukkan pada Tabel 9 .

Tabel 9. Tanggapan Responden Bahwa Warna Kacang Edamame yang Bagus Adalah Warna Hijau Merata

\begin{tabular}{clcc}
\hline $\begin{array}{c}\text { Nilai } \\
(\boldsymbol{a})\end{array}$ & \multicolumn{1}{c}{ Jawaban } & $\begin{array}{c}\text { Persentase } \\
(\boldsymbol{b}) /(\boldsymbol{\%})\end{array}$ & $\begin{array}{c}\text { Skor } \\
(\boldsymbol{a}) \boldsymbol{x}(\boldsymbol{b})\end{array}$ \\
\hline 5 & Sangat Setuju & 54 & 270 \\
4 & Setuju & 45 & 180 \\
3 & Netral & 1 & 3 \\
2 & Tidak Setuju & 0 & 0 \\
1 & Sangat Tidak Setuju & 0 & 0 \\
\hline \multicolumn{2}{l}{ Jumlah } & $\mathbf{1 0 0}$ & $\mathbf{4 5 3}$ \\
\hline
\end{tabular}

Sumber: Hasil Pengolahan Data Primer dengan SPSS, 2020.

Hasil penelitian menunjukkan bahwa respon-den sangat setuju bahwa warna kacang edamame yang bagus dan layak untuk dibeli adalah hijau merata.

\section{2) Harga (X2)}

Hasil tanggapan responden mengenai keterjangkauan harga kacang edamame ditunjukkan pada Tabel 10. Hasil penelitian menunjukkan bahwa 93\% responden setuju bahwa harga kacang edamame cukup terjangkau. Hal ini menunjukkan bahwa harga kacang edamame masih mampu dibayar oleh konsumen.

Tabel 10.Tanggapan Responden Bahwa Harga Kacang Edamame Terjangkau

\begin{tabular}{clcc}
\hline $\begin{array}{c}\text { Nilai } \\
(\boldsymbol{a})\end{array}$ & \multicolumn{1}{c}{ Jawaban } & $\begin{array}{c}\text { Persentase } \\
(\boldsymbol{b}) /(\mathbf{\%})\end{array}$ & $\begin{array}{c}\text { Skor } \\
(\boldsymbol{a}) \boldsymbol{x}(\boldsymbol{b})\end{array}$ \\
\hline 5 & Sangat Setuju & 44 & 44 \\
4 & Setuju & 49 & 49 \\
3 & Netral & 7 & 7 \\
2 & Tidak Setuju & 0 & 0 \\
1 & Sangat Tidak Setuju & 0 & 0 \\
\hline Jumlah & $\mathbf{1 0 0}$ & $\mathbf{4 3 7}$ \\
\hline \multicolumn{2}{l}{ Sumber: Hasil Pengolahan Data Primer dengan SPSS, 2020. }
\end{tabular}

\section{3) Tempat (X3)}

Konsumen memerlukan pertimbangan yang cermat dalam pemilihan tempat berbelanja terutama pada situasi pandemi COVID-19, di mana pergerakan masyarakat sangat diperketat dan dibatasi jumlah pengunjung yang masuk ke dalam pasar swalayan. Berdasarkan hasil penelitian, sebesar 57\% responden setuju dengan kestrategisan lokasi penjualan kacang edamame. Hal ini terlihat dari letaknya pasar swalayan ada di pinggir jalan raya dan dekat permukiman penduduk, seperti Transmart Carrefour Buaran yang terletak di pinggir Jalan Raya Raden Inten II dan AEON Hypermart JGC terletak di permukiman penduduk yaitu di Jakarta Garden City (JGC).

\section{4) Promosi (X4)}

Promosi adalah insentif jangka pendek untuk meningkatkan pembelian atau penjualan produk yang diharapkan dapat terjadi pembelian produk pada saat itu juga. Studi menunjukkan bahwa $87 \%$ responden setuju bahwa adanya pengaruh untuk membeli kacang edamame karena adanya informasi promosi untuk kacang edamame. Hal ini dikarenakan menurut responden penyampaian iklan promosi cenderung menarik dan mampu menciptakan pesan untuk konsumen membeli kacang edamame. Informasi mengenai promosi berupa tulisan cetak yang diletakan di sekitar produk serta pengumuman (informasi dalam bentuk audio) dari wiraniaga atau petugas pasar swalayan untuk mengumumkan adanya potongan harga.

\section{5) Bukti Fisik (X5)}

Bukti fisik adalah keadaan, kondisi atau suasana tempat dipasarkannya sebuah produk atau jasa (Kotler \& Keller, 2012). Berdasarkan hasil penelitian, dapat diketahui bahwa sebesar 84 $\%$ responden sangat setuju bahwa konsumen dipermudah dengan fasilitas yang tersedia di pasar swalayan. Hal tersebut didukung dengan adanya fasilitas pembayaran non-tunai, fasilitas parkir, tempat ibadah, toilet, ATM, eskalator, lift serta fasilitas keamanan seperti CCTV dan petugas keamanan yang mendukung keamanan dan kenyamanan konsumen saat berbelanja. Fasilitas lainnya yang disediakan oleh pasar swalayan untuk mendukung program pemerintah Provinsi DKI Jakarta adalah mengurangi penggunaan plastik belanja dengan menyediakan tas belanja ramah lingkungan dan kardus bekas untuk pengemasan barang-barang yang telah dibeli oleh konsumen. Selain itu, protokol kesehatan juga sangat diperhatikan di situasi pandemi COVID-19 
saat ini. Pengunjung pasar swalayan diwajibkan untuk melakukan pengecekan suhu tubuh, pemberian hand sanitizer dan pemberian masker mulut (jika pengunjung tidak menggunakan masker yang sesuai dengan protokol kesehatan) sebelum diperbolehkan untuk masuk ke pasar swalayan. Pengunjung juga diwajibkan mengambil nomor antrian untuk masuk dan berbelanja di pasar swalayan. Tentunya tindakan-tindakan tersebut sangat berpengaruh untuk menjamin keamanan, kenyamanan dan kesehatan konsumen saat sedang berbelanja.

\section{TAHAPAN-TAHAPAN DALAM PENGAMBILAN KEPUTUSAN PEMBELIAN KACANG EDAMAME}

Keputusan pembelian merupakan suatu metode pemecahan masalah dalam aktivitas manusia untuk membeli barang yang sesuai dengan kebutuhannya. Ini mencakup tahapan berikut:

\section{1) Pengenalan Kebutuhan}

Konsumen yang membeli kacang edamame didasari dengan persepsi untuk mendapatkan value berupa kualitas produk yang menjanjikan, harga yang sesuai, promosi menarik maupun lingkungan pasar swalayan yang memungkinkan tersampaikannya produk tersebut kepada konsumen. Hal tersebut dapat memicu alasan utama konsumen dalam mengenali kebutuhannya untuk membeli kacang edamame. Kegiatan pengenalan kebutuhan dalam proses pengambilan keputusan pembelian kacang edamame sebagai berikut:

\section{Tabel 11. Tujuan Membeli Kacang Edamame}

\begin{tabular}{lcc}
\hline \multicolumn{1}{c}{ Tujuan } & $\begin{array}{c}\text { Jumlah } \\
\text { (orang) }\end{array}$ & $\begin{array}{c}\text { Persentase } \\
\text { (\%) }\end{array}$ \\
\hline $\begin{array}{l}\text { Untuk dikonsumsi sendiri } \\
\text { atau keluarga }\end{array}$ & 60 & 60 \\
Untuk diolah (cth: susu & & \\
edamame, MPASI) & 11 & 11 \\
Ada promosi khusus & 25 & 25 \\
Manfaat kacang edamame & 4 & 4 \\
\hline Jumlah & $\mathbf{1 0 0}$ & $\mathbf{1 0 0}$ \\
\hline Sumber: Hasil Pengolahan Data Primer dengan SPSS, 2020.
\end{tabular}

Tabel 11 menunjukkan bahwa rata-rata tujuan konsumen membeli kacang edamame untuk dikonsumsi sendiri atau keluarga adalah sebesar $60 \%$. Selanjutnya dapat diketahui frekuensi responden melakukan kunjungan ke pasar swalayan sebagai berikut:
Tabel 12. Frekuensi Kunjungan ke Pasar Swalayan

\begin{tabular}{lcc}
\hline \multicolumn{1}{c}{ Frekuensi kunjungan } & $\begin{array}{c}\text { Jumlah } \\
\text { (orang) }\end{array}$ & $\begin{array}{c}\text { Persentase } \\
\text { (\%) }\end{array}$ \\
\hline $\begin{array}{l}\text { Tiap Minggu } \\
\text { (4 kali dalam sebulan) }\end{array}$ & 27 & 27 \\
$\begin{array}{l}\text { Tiap Bulan } \\
\text { (1 kali dalam sebulan) }\end{array}$ & 73 & 73 \\
\hline Jumlah & $\mathbf{1 0 0}$ & $\mathbf{1 0 0}$ \\
\hline
\end{tabular}

Sumber: Hasil Pengolahan Data Primer dengan SPSS, 2020.

Hasil pada Tabel 12 menunjukkan frekuensi responden berkunjung ke pasar swalayan sebanyak 1 kali dalam sebulan adalah sebesar 73\%. Sedangkan, frekuensi responden berkunjung sebanyak 4 kali dalam sebulan adalah sebesar $27 \%$. Frekuensi konsumen yang berkunjung ke pasar swalayan didominasi oleh responden yang datang hanya sekali dalam sebulan dikarenakan penelitian ini dilaksanakan dalam keadaan pandemi COVID-19, di mana masyarakat Jakarta Timur sedang dalam tahap Pembatasan Sosial Berskala Besar (PSBB), yaitu masyarakat dihimbau untuk membatasi aktivitas di luar rumah untuk menghambat rantai penyebaran virus COVID-19.

\section{2) Pencarian Informasi}

Kegiatan pencarian informasi yang dilakukan oleh konsumen untuk mencapai keputusan pembelian sebagai berikut:

\section{Tabel 13. Sumber Informasi}

\begin{tabular}{lcc}
\hline \multicolumn{1}{c}{ Sumber informasi } & $\begin{array}{c}\text { Jumlah } \\
\text { (orang) }\end{array}$ & $\begin{array}{c}\text { Persentase } \\
\text { (\%) }\end{array}$ \\
\hline Internet atau Sosial Media & 9 & 9 \\
Keluarga atau Teman & 15 & 15 \\
Pengalaman pribadi & 49 & 49 \\
Promosi di Pasar Swalayan & 27 & 27 \\
\hline Jumlah & $\mathbf{1 0 0}$ & $\mathbf{1 0 0}$
\end{tabular}

Sumber: Hasil Pengolahan Data Primer, 2020.

Berdasarkan Tabel 13, dapat diketahui bahwa mayoritas responden mendapatkan sumber informasi mengenai kacang edamame berasal dari pengalaman pribadi atau sebesar 49\%. Pengalaman pribadi yang dialami oleh konsumen dapat berupa melihat produk secara langsung dan menganalisis secara visual bagaimana bentuk fisik dan kegunaan dari produk tersebut. Selain itu pengalaman pribadi yang dimaksud oleh konsumen juga berupa pengalaman mengkonsumsi kacang edamame yang sudah siap di konsumsi di restoran, khususnya restoran jepang. Berdasar- 
kan pengalaman tersebut, konsumen tertarik untuk membeli kembali kacang edamame dalam bentuk fresh di pasar swalayan.

\section{3) Evaluasi Alternatif}

Pada tahap ini, konsumen mengevaluasi pilihannya sesuai dengan manfaat yang diharapkan. Pertimbangan dalam mengambil keputusan pembelian sebagai berikut:

Tabel 14. Pertimbangan dalam Membeli Kacang Edamame

\begin{tabular}{lcc}
\hline $\begin{array}{c}\text { Faktor yang } \\
\text { dipertimbangkan }\end{array}$ & $\begin{array}{c}\text { Jumlah } \\
\text { (orang) }\end{array}$ & $\begin{array}{c}\text { Persentase } \\
\text { (\%) }\end{array}$ \\
\hline Lokasi Penjualan & 1 & 1 \\
Harga produk & 23 & 23 \\
Ketersediaan produk & 12 & 12 \\
Mutu produk (manfaat) & 30 & 30 \\
Promosi produk & 34 & 34 \\
\hline Jumlah & $\mathbf{1 0 0}$ & $\mathbf{1 0 0}$ \\
\hline Sumber: Hasil Pengolahan Data Primer dengan SPSS, 2020.
\end{tabular}

Berdasarkan Tabel 14, dapat diketahui dapat diketahui bahwa pertimbangan utama responden dalam menentukan pembelian kacang edamame adalah promosi produk. Hal ini dikarenakan terdapat promosi potongan harga sebesar 35\% untuk setiap pembelian 500gr kacang edamame dengan harga Rp12.800,- AEON Hypermart JGC dan promosi "super ECO" di Carrefour Lippo Mall dengan harga Rp10.000,- per 500 gram. Atribut yang paling diperhatikan oleh konsumen saat ingin membeli kacang edamame adalah tampilan kemasan kacang edamame yang menarik, kokoh dan bersih. Hal ini sejalan dengan pernyataan Wells et al. (2007) dalam Darmawan (2017) bahwa kemasan produk memiliki peran sebagai alat pertimbangan untuk membantu konsumen dalam memutuskan pembelian produk dari berbagai produk sejenis.

\section{4) Pembelian}

Tahap keputusan pembelian dapat dijelaskan sebagai berikut:

\section{Tabel 15. Cara Responden Memutuskan} Pembelian

\begin{tabular}{lrr}
\hline \multicolumn{1}{c}{$\begin{array}{c}\text { Cara Memutuskan } \\
\text { Pembelian }\end{array}$} & $\begin{array}{c}\text { Jumlah } \\
\text { (orang) }\end{array}$ & $\begin{array}{c}\text { Persentase } \\
\text { (\%) }\end{array}$ \\
\hline Telah direncanakan & 68 & 68 \\
$\begin{array}{l}\text { Tidak direncanakan atau } \\
\text { tergantung situasi }\end{array}$ & 32 & 32 \\
\hline Jumlah & $\mathbf{1 0 0}$ & $\mathbf{1 0 0}$ \\
\hline Sumber: Hasil Pengolahan Data Primer dengan SPSS, 2020.
\end{tabular}

Promosi yang menarik, seperti menerapkan strategi promosi produk dengan "potongan harga", dapat menarik minat konsumen untuk membeli.

\section{5) Perilaku Pasca Pembelian}

Tahap terakhir dalam proses keputusan pembelian sebagai berikut:

Tabel 16. Tingkat Kepuasan Konsumen

\begin{tabular}{lrc}
\hline \multicolumn{1}{c}{ Tingkat Kepuasan } & $\begin{array}{r}\text { Jumlah } \\
\text { (orang) }\end{array}$ & $\begin{array}{r}\text { Persentase } \\
\text { (\%) }\end{array}$ \\
\hline Sangat Puas & 52 & 52 \\
Puas & 48 & 48 \\
Tidak Puas & 0 & 0 \\
Sangat Tidak Puas & 0 & 0 \\
\hline Jumlah & $\mathbf{1 0 0}$ & $\mathbf{1 0 0}$ \\
\hline
\end{tabular}

Sumber: Hasil Pengolahan Data Primer dengan SPSS, 2020

Berdasarkan Tabel 16, dapat diketahui bahwa sebagian besar konsumen merasa puas dengan produk kacang edamame. Beberapa penilaian utama yang dapat membangun tingkat kepuasan responden adalah berdasarkan respons dari konsumen mengenai kualitas kacang edamame yang bermutu, seperti harga yang sesuai, kemasan yang kuat dan kacang yang bersih. Data pada Tabel 16 juga menunjukkan bahwa hampir semua responden menyatakan bersedia untuk melakukan pembelian ulang. Konsumen merasa puas dan responden termotivasi untuk melakukan pembelian ulang karena kacang edamame memiliki spesifikasi yang memenuhi harapan konsumen. Selain melakukan pembelian ulang, konsumen kemudian akan memberikan rekomendasi kepada orang lain atau juga disebut word of mouth (WOM). Hal ini sesuai dengan pernyataan Kotler \& Keller (2012), yaitu WOM merupakan proses komunikasi berupa pemberian rekomendasi dan informasi mengenai produk atau jasa yang telah digunakan dan kemudian dianjurkan oleh konsumen sebelumnya.

\section{Hasil Rekapitulasi Skoring Bauran Pemasaran dan Keputusan Pembelian Kacang Edamame}

Menurut Sugiyono (2018), analisis deskripsi dapat disimpulkan berdasarkan data rekapitulasi skoring penelitian. Skor standar yang diperoleh dari perhitungan digunakan untuk menentukan daerah kontinum dan wilayah ideal dari setiap variabel yang diteliti. 
Garis kontinum adalah garis yang digunakan untuk menganalisis, mengukur dan menunjukkan seberapa besar tingkat kekuatan variabel penelitian. Hasil studi menunjukkan bahwa total skor untuk 35 butir pertanyaan dan 100 responden adalah sebesar 14.317; skor untuk pelaksanaan bauran pemasaran (29 butir pertanyaan) sebesar 11.811 dan skor untuk keputusan pembelian (6 butir) sebesar 2.506 .

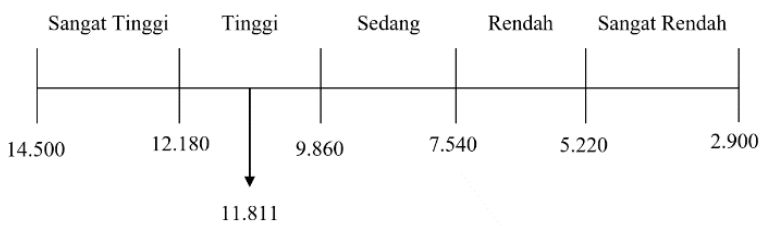

\section{Gambar 1. Garis Kontinum Bauran Pemasaran. \\ Sumber: Hasil Pengolahan Data, 2020}

Hasil perhitungan data menunjukkan bahwa pelaksanaan bauran pemasaran kacang edamame di pasar swalayan adalah sebesar 81,5\% $(11.811 / 14.500 \times 100 \%)$ ada pada interval tinggi pada garis kontinum. Hal tersebut menandakan bahwa kinerja bauran pemasaran menurut responden terlaksana dengan baik dan semua unsur dari bauran pemasaran ikut berperan dalam melaksanakan kegiatan pemasaran kacang edamame. Pelaksanaan bauran pemasaran meliputi bentuk fisik produk kacang edamame, harga produk, tempat produk dapat ditemukan, promosi dan informasi yang tersampaikan serta lingkungan fisik pasar swalayan yang mendukung responden dalam berbelanja.

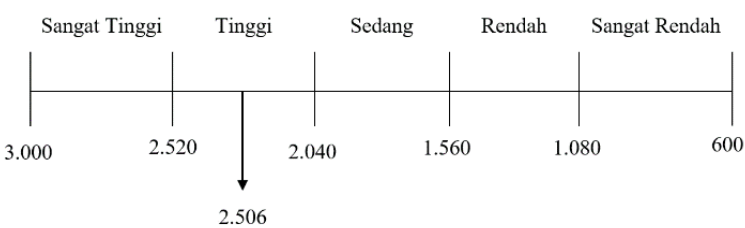

\section{Gambar 2. Garis Kontinum Keputusan Pembelian.}

Sumber: Hasil Pengolahan Data, 2020

Hasil perhitungan data mengenai tanggapan responden mengenai keputusan pembelian menurut 100 orang responden adalah sebesar 83,5 persen (2.506/3.000 x 100 persen). Hal ini berarti keputusan konsumen untuk melakukan pembelian kacang edamame yang dinilai oleh responden sebesar 83,5 persen dari skor maksimal yang dapat dicapai yaitu 100 persen, sehingga pelaksanaan keputusan pembelian berada pada kategori tinggi.

\section{PENGARUH BAURAN PEMASARAN TERHADAP KEPUTUSAN PEMBELIAN KACANG EDAMAME}

\section{Pengaruh Secara Simultan}

Menurut Riduwan et al. (2017), untuk menghitung koefisien jalur secara simultan ditunjukkan pada hasil R Square atau R²X'Y. Hasil pengaruh secara simultan sebagai berikut:

\section{Tabel 17. Model Summary}

\begin{tabular}{lcccc}
\hline $\mathbf{R}$ & $\begin{array}{c}\text { R } \\
\text { Square }\end{array}$ & $\begin{array}{c}\text { Adjusted } \\
\text { R Square }\end{array}$ & $\begin{array}{c}\text { Std. Error of } \\
\text { the Estimate }\end{array}$ & $\begin{array}{c}\text { Durbin- } \\
\text { Watson }\end{array}$ \\
\hline $.791^{\text {a }}$ & .626 & .606 & .968 & 1.718 \\
\hline a. Predictors: (Constant), Bukti_Fisik, Produk, Harga, Promosi, \\
Tempat \\
b. Dependent Variable: Keputusan_Pembelian \\
Sumber: Hasil Pengolahan Data Primer dengan SPSS, 2020.
\end{tabular}

Berdasarkan Tabel 17, dapat diketahui bahwa besarnya kontribusi produk (X1), harga (X2), tempat (X3), promosi (X4), dan bukti fisik (X5) secara simultan yang langsung mempengaruhi keputusan pembelian (Y) adalah sebesar 0,626 atau sebesar $62,6 \%$. Koefisien residu adalah pengaruh variabel lain di luar model yang tidak ikut diamati, adalah sebesar $37,4 \%\left(0,61^{2}=0,374\right)$.

\section{Pengaruh Secara Langsung dan Tidak Langsung}

Menurut Riduwan et al. (2017), koefisien jalur ditunjukkan oleh output yang dinyatakan sebagai Standardized Coefficient (nilai Beta). Metode perhitungan untuk mengetahui bobot persentase pengaruh langsung variabel eksogen terhadap variabel endogen adalah dengan menkuadratkan nilai koefisien jalur $\left(\left(\mathrm{PX}^{\prime} \mathrm{Y}\right)^{2}\right)$, sedangkan untuk mengetahui pengaruh tidak langsung atau pengaruh yang di mediasi oleh variabel independen lainnya adalah dengan mengkalikan koefisien jalur dengan koefisien korelasi antar variabel. Berikut Perhitungan pengaruh langsung dan tidak langsung: 
Tabel 18. Coefficients ${ }^{a}$

\begin{tabular}{lrrrrr}
\hline \multirow{1}{*}{ Model } & \multicolumn{2}{c}{$\begin{array}{c}\text { Unstandardized } \\
\text { Coefficients }\end{array}$} & \multicolumn{2}{c}{$\begin{array}{c}\text { Standardized } \\
\text { Coefficients }\end{array}$} & \multirow{2}{*}{ Sig. } \\
\cline { 2 - 5 } & \multicolumn{1}{c}{ B } & $\begin{array}{c}\text { Std. } \\
\text { Error }\end{array}$ & Beta & t & \\
\hline Constant & 5.024 & 1.687 & & 2.978 & .004 \\
Produk & .131 & .055 & .194 & 2.409 & .018 \\
Harga & .220 & .084 & .199 & 2.617 & .010 \\
Tempat & .111 & .051 & .192 & 2.171 & .032 \\
Promosi & .232 & .086 & .220 & 2.698 & .008 \\
Bukti Fisik & .214 & .087 & .216 & 2.460 & .016 \\
\hline a. Dependent Variable: Keputusan Pembelian \\
Sumber: Hasil Pengolahan Data Primer dengan SPSS, 2020.
\end{tabular}

Berdasarkan Tabel 18, dapat diketahui bahwa koefisien jalur untuk variabel bauran pemasaran (X) atau produk (X1) adalah 0,194; harga (X2) adalah 0,199; tempat (X3) adalah 0,192 ; promosi (X4) adalah 0,220 dan bukti fisik (X5) adalah 0,216.

Tabel 19. Pengaruh Langsung dan Tidak Langsung

\begin{tabular}{cccccccc}
\hline $\mathbf{X}$ & \multicolumn{2}{c}{$\begin{array}{c}\text { Pengaruh Tidak Langsung } \\
\text { Melalui Variabel Xi (\%) }\end{array}$} & $\begin{array}{c}\text { Pengaruh } \\
\text { Langsung } \\
\text { (pxiy }^{2} \text { ) (\%) }\end{array}$ & $\begin{array}{c}\text { Pengaruh } \\
\text { Total (\%) }\end{array}$ \\
\hline & X1 & X2 & X3 & X4 & X5 & & \\
\hline X1 & - & 1,69 & 2,02 & 2,07 & 2,05 & 3,76 & 11,6 \\
X2 & 1,69 & - & 1,64 & 2,11 & 2,14 & 3,97 & 11,2 \\
X3 & 2,02 & 1,64 & - & 2,35 & 2,44 & 3,69 & 12,3 \\
X4 & 2,07 & 2,11 & 2,35 & - & 2,53 & 4,84 & 13,9 \\
X5 & 2,05 & 2,14 & 2,44 & 2,53 & - & 4,64 & 13,6 \\
\hline \multicolumn{7}{c}{ Jumlah } \\
\hline
\end{tabular}

Sumber: Hasil Pengolahan Data Primer SPSS, 2020.

Berdasarkan Tabel 19, pengaruh variabel independen eksogen terhadap variabel dependen endogen secara parsial sebagai berikut:

a) Pengaruh variabel X1 terhadap Y (PX1Y)

Besarnya konstribusi produk (X1) yang secara langsung mempengaruhi keputusan pembelian (Y) adalah sebesar 0,194 atau 3,76\%. Pengaruh tidak langsung variabel produk yang di mediasi oleh variabel harga, tempat, promosi dan bukti fisik memberikan nilai pengaruh tidak langsung sebesar 7,84\%. Besarnya kontribusi produk secara keseluruhan adalah sebesar 11,6\%.

b) Pengaruh variabel X2 terhadap Y (PX2Y) Besarnya konstribusi harga (X2) yang secara langsung mempengaruhi keputusan pembelian $(\mathrm{Y})$ adalah 0,199 atau 3,96\%. Pengaruh tidak langsung variabel harga yang di mediasi oleh variabel produk, tempat, promosi dan bukti fisik memberikan nilai pengaruh tidak langsung sebesar 7,23\%. Besarnya kontribusi variabel harga terhadap secara keseluruhan adalah sebesar $11,2 \%$.

c) Pengaruh variabel X3 terhadap Y (PX3Y) Besarnya konstribusi tempat (X3) yang secara langsung mempengaruhi keputusan pembelian (Y) adalah 0,192 atau sebesar 3,69\%. Pengaruh tidak langsung variabel tempat yang di mediasi oleh variabel produk, harga, promosi dan bukti fisik memberikan nilai pengaruh tidak langsung sebesar 8,61\%. Besarnya kontribusi variabel tempat terhadap keputusan pembelian secara keseluruhan adalah sebesar $12,3 \%$.

d) Pengaruh variabel X4 terhadap Y (PX4Y)

Besarnya konstribusi promosi (X4) yang secara langsung mempengaruhi keputusan pembelian (Y) adalah 0,220 atau 4,84\%. Pengaruh tidak langsung variabel promosi yang di mediasi oleh variabel produk, tempat, harga dan bukti fisik memberikan nilai pengaruh tidak langsung sebesar 9,06 \%. Besarnya kontribusi variabel promosi secara keseluruhan adalah sebesar 13,9\%.

e) Pengaruh variabel X5 terhadap Y (PX5Y)

Besarnya konstribusi bukti fisik (X5) yang secara langsung mempengaruhi keputusan pembelian (Y) adalah 0,216 atau sebesar 4,67\%. Pengaruh tidak langsung variabel bukti fisik yang di mediasi oleh variabel produk, tempat, promosi dan harga memberikan nilai pengaruh tidak langsung sebesar 8,96\%. Besarnya kontribusi variabel harga secara keseluruhan adalah $13,6 \%$.

Persamaan strukturalnya adalah:

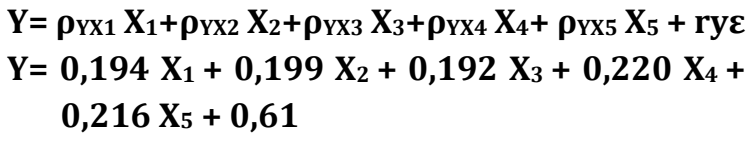

Berdasarkan perhitungan koefisien korelasi, koefisien jalur dan koefisien residu, nilai tersebut dapat disajikan dalam bentuk diagram jalur sebagai berikut: 


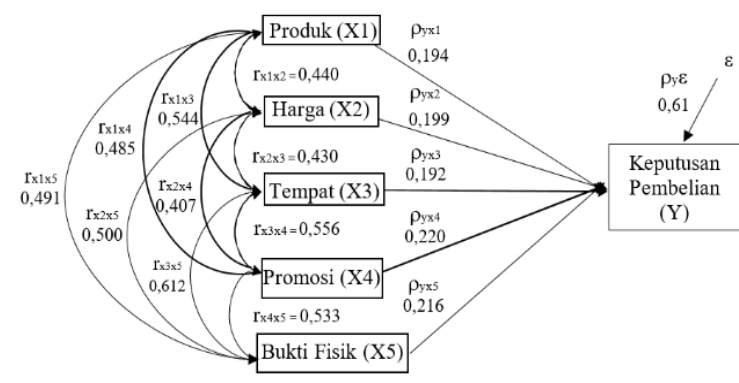

Gambar 3. Diagram Jalur Hasil Perhitungan Analisis Jalur.

Sumber : Hasil Pengolahan Data, 2020

\section{VARIABEL BAURAN PEMASARAN YANG PALING BERPENGARUH TERHADAP KEPUTUSAN PEMBELIAN KACANG EDAMAME}

\section{1) Uji F}

Tabel 20 menyatakan bahwa nilai $F_{\text {hitung }}$ yang diperoleh adalah sebesar 31,483 dengan angka signifikansi sebesar 0,000. Nilai tersebut lebih besar dibandingkan nilai $\mathrm{F}_{\text {tabel }}$ yaitu 2,31. Maka kesimpulan hipotesisnya adalah HO ditolak dan Ha diterima, yang artinya variabel produk (X1), harga (X2), tempat (X3), promosi (X4) dan bukti fisik (X5) secara bersama-sama berpengaruh signifikan terhadap variabel keputusan pembelian (Y). Berikut hasil uji F:

Tabel 20. ANOVAa

\begin{tabular}{lrrrrr}
\hline \multicolumn{1}{c}{ Model } & $\begin{array}{c}\text { Sum of } \\
\text { Square }\end{array}$ & df & $\begin{array}{c}\text { Mean } \\
\text { Square }\end{array}$ & F & Sig, \\
\hline Regression & 147.539 & 5 & 29.508 & 31.483 & $.000^{\mathrm{b}}$ \\
Residual & 88.101 & 94 & .937 & & \\
Total & 235.640 & 99 & & & \\
\hline
\end{tabular}

a. Dependent Variable: Keputusan Pembelian

b. Predictors: (Constant), Bukti Fisik, Produk, Harga, Promosi, Tempat

Sumber: Hasil Pengolahan Data Primer 2020.

\section{2) Uji t}

Berdasarkan hasil uji t parsial pada Tabel 18, dapat disimpulkan bahwa:

1. Produk (X1)

Nilai thitung sebesar 2,409 > tabel 1,986 pada taraf signifikansi $5 \%$. Nilai koefisien jalur variabel produk (X1) adalah sebesar 0,194 yaitu lebih besar dari $0(\rho \mathrm{YX} 1>0)$. Ho ditolak dan Ha diterima, yang berarti variabel produk secara individual berpengaruh positif secara signifikan terhadap variabel keputusan pembelian.
2. Harga (X2)

Nilai thitung sebesar 2,617 > tabel 1,986 pada taraf signifikansi $5 \%$. Nilai koefisien jalur variabel harga (X2) adalah sebesar 0,199 yaitu lebih besar dari $0(\rho \mathrm{YX} 2>0)$. Ho ditolak dan Ha diterima, yang berarti variabel harga secara individual berpengaruh positif secara signifikan terhadap variabel keputusan pembelian.

3. Tempat (X3)

Nilai thitung sebesar 2,171 $>t_{\text {tabel }} 1,986$ pada taraf signifikansi $5 \%$. Nilai koefisien jalur variabel tempat (X3) adalah sebesar 0,192 yaitu lebih besar dari $0(\rho Y X 3>0)$. Ho ditolak dan Ha diterima, yang berarti variabel tempat secara individual berpengaruh positif secara signifikan terhadap variabel keputusan pembelian.

4. Promosi (X4)

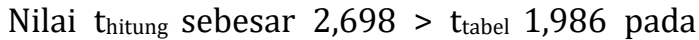
taraf signifikansi $5 \%$. Nilai koefisien jalur variabel promosi (X4) adalah sebesar 0,220 yaitu lebih besar dari $0(\rho \mathrm{YX} 4>0)$. Ho ditolak dan Ha diterima, yang berarti variabel promosi secara individual berpengaruh positif secara signifikan terhadap variabel keputusan pembelian.

5. Bukti Fisik (X5)

Nilai thitung sebesar $2,460>$ tabel 1,986 pada taraf signifikansi $5 \%$. Nilai koefisien jalur variabel bukti fisik (X3) adalah sebesar 0,216 yaitu lebih besar dari 0 ( $\rho$ YX5 $>0$ ). Ho ditolak dan Ha diterima, yang berarti variabel bukti fisik secara individual berpengaruh positif secara signifikan terhadap variabel keputusan pembelian.

Berdasarkan uji t parsial dapat disimpulkan bahwa variabel bebas yang berpengaruh secara dominan terhadap keputusan pembelian kacang edamame adalah variabel promosi (X4) dengan nilai thitung sebesar 2,698 lebih besar dari nilai tabel $1,986(2,698>1,986)$ pada tingkat signifikansi $5 \%$ $(0,05)$. Perhitungan tersebut juga didukung dengan hasil perhitungan analisis jalur yaitu variabel eksogen promosi (X4) memberikan kontribusi yang paling besar terhadap keputusan pembelian kacang edamame yaitu sebesar 13,9\% dari total pengaruh variabel bauran pemasaran terhadap keputusan pembelian yaitu $62,6 \%$. Hal ini menunjukkan bahwa kegiatan promosi dalam 
penyampaian informasi yang efektif dan bersifat persuasif dapat mempengaruhi konsumen dalam melakukan pembelian. Keingintahuan konsumen terhadap manfaat kacang edamame dan adanya promosi yang ditawarkan oleh pasar swalayan merupakan hal yang mendukung konsumen untuk tertarik dalam melakukan pembelian kacang edamame.

\section{SIMPULAN DAN SARAN}

\section{SIMPULAN}

Berdasarkan hasil penelitian, dapat disimpulkan bahwa:

1. Persepsi konsumen terhadap pelaksanaan bauran pemasaran produk kacang edamame pada pasar swalayan di Kota Jakarta Timur berada pada kategori tinggi yang artinya konsumen setuju bauran pemasaran kacang edamame sudah terlaksana dengan baik.

2. Tahapan-tahapan yang dilakukan konsumen dalam proses pengambilan keputusan pembelian kacang edamame pada pasar swalayan di Kota Jakarta Timur meliputi: pengenalan kebutuhan, pencarian informasi, evaluasi alternatif, pembelian, dan perilaku pasca pembelian berada pada kategori tinggi yang artinya konsumen setuju hal tersebut sudah terlaksana dengan baik.

3. Bauran pemasaran secara simultan berpengaruh positif dan signifikan terhadap keputusan pembelian kacang edamame pada pasar swalayan di Kota Jakarta Timur.

4. Variabel bauran pemasaran yang paling berpengaruh terhadap keputusan pembelian kacang edamame pada pasar swalayan di Kota Jakarta Timur adalah variabel promosi (X4).

\section{SARAN}

Saran yang dapat diberikan berdasarkan penelitian adalah:

1. Menjaga kebersihan produk, memberi potongan harga, meletakkan kacang edamame pada tempat atau rak display yang mudah terlihat.

2. Meningkatkan variasi promosi seperti "potongan harga", meningkatkan penyebarluasan informasi promosi berupa pengumuman informasi, baik dari media cetak maupun pramuniaga, serta menjaga kenyamanan pasar swalayan sebagai upaya-upaya untuk meningkatkan potensi dan frekuensi konsumen dalam melakukan pembelian kacang edamame.

\section{DAFTAR PUSTAKA}

Abidin, Z., Nuddin, H., \& Boimin. 2017. Analisis Strategi Bauran Pemasaran Terhadap Keputusan Pembelian Bandeng Presto "Bu Jeni" di Kota Malang, Jawa Timur. Journal of Economic and Social of Fisheries and Marine, 2017, 05(01) 30-4. Malang (ID): Universitas Brawijaya.

Afifah, A. N., Rahayu, E. S., \& Setyowati. Analisis Pengaruh Bauran Pemasaran terhadap Keputusan Pembelian Buah Apel di Pasar Swalayan Kota Surakarta. [skripsi]. Surakarta (ID): Universitas Sebelas Maret Surakarta.

Amin, M. A., \& Dwi, J. 2017. Klasifikasi Kelompok Umur Manusia Berdasarkan Analisis Dimensi Fraktal Box Counting dari Citra Wajah dengan Deteksi Tepi Canny. Jurnal Ilmiah Matematika 2(6):33-42. Universitas Negeri Surabaya.

(BPS) Badan Pusat Statistik Kota Jakarta Timur. 2020. Kota Jakarta Timur Dalam Angka 2020, Penyediaan Data untuk Perencanaan Pembangunan. Jakarta (ID): BPS Jakarta.

Coolong, T. 2009. Edamame. College of Agriculture, Kentucky (US): University of Kentucky,

Darmawan, D. 2017. Pengaruh Kemasan dan Harga Terhadap Keputusan Pembelian Produk Sayuran Hidroponik. Jurnal Agrimas Vol 1(1): 1-10.

Dinas Kelautan, Pertanian dan Ketahanan Pangan Provinsi DKI Jakarta. 2015. Data Pasar Jakarta Timur (On-line), http://ketahananpangandki.com/jakarta ti mu/pasar/3.html ,diakses pada 27 Februari 2020.

Fitriyono, D. \& Khuzaini. 2014. Analisis Pengaruh Bauran Pemasaran Terhadap Volume Penjualan Produk. Jurnal Ilmu \& Riset Manajemen Vol. 3. No. 11. 
Ghozali, I. 2009. Aplikasi Analisis Multivariate Dengan Program SPSS (Edisi ke 4). Semarang (ID): Universitas Diponegoro.

Hurriyati, R. 2005. Bauran Pemasaran dan Loyalitas Konsumen. Bandung (ID): Alfabeta.

Konovsky, J. 2004. Understanding The Japanese Food and Agrimarket: A Multifaceted Opportunity. Binghamton (US): Haworth Press.

Kotler, P. \& Armstrong, G. 2008. Prinsip-Prinsip Pemasaran Jilid 1 (Edisi ke 12), Jakarta (ID): Penerbit Erlangga.

Kotler \& Keller. 2012. Manajemen Pemasaran Edisi 12. Jakarta (ID): Penerbit Erlangga.

Medianti, U. S. 2019. Indonesia Ekspor 115 Ton Edamame ke Jepang (On-line), https://finance.detik.com/berita-ekonomibisnis/d-4660594/indonesia-ekspor-115ton-edamame-ke-jepang diakses pada 19 Desember 2019.

Pebriani, A, R. 2019. Faktor Budaya Mempengaruhi Keputusan Pembelian Kacang Kedelai Jepang Edamame (Glycin Max) di Berastagi Supermarket Gatot Subroto dan Lotte Mart Centre Point Mall Medan. Skripsi. Medan (ID): Universitas Muhammadiyah Sumatera Utara.

Prayoga, K, G. 2017. Analisis Pengaruh Bauran Terhadap Keputusan Pembelian Produk Brand Extension Minimarket Indomaret. [skripsi]. Bogor (ID): Fakultas Ekonomi dan Manajemen, Institut Pertanian Bogor.

Priyatno, D. 2012. Cara Kilat Belajar Analisis Data dengan SPSS 20. Yogyakarta (ID): Andi Offset.

Rackis, J. J. 1978. Biochemical changes in soybeans: maturation post-harvest storage and processing and germination. Pages 34-76 In H.O. Hultin and M. Milner (eds). Postharvest Biology and Technology. Food and Nutrition. Westport (US)

Riduwan., Engkos, A. K., \& Akdon. 2017. Cara Menggunakan dan Memaknai Path Analysis ( $7^{\text {th }}$ ed.). Bandung (ID): Penerbit Alfabeta.
Sari, E. S. 1993. Audience Research: Pengantar Studi Penelitian Terhadap Pembaca, Pendegar dan Pemirsa. Yogyakarta (ID): Penerbit Andi Offset.

Sarwoko. 2005. Dasar-dasar Ekonometrika, Yogyakarta (ID): Penerbit ANDI.

Sarwono, J. 2012. Path Analysis dengan SPSS: Teori, Aplikasi, Prosedur Analisis untuk Riset Skripsi, Tesis dan Disertasi. Jakarta (ID): PT. Elix Media Komputindo.

Sugiyono. 2018. Metode Penelitian Kuantitatif, Kualitatif, dan $R \& D$. Bandung (ID): Alfabeta.

Sumarwan, U. 2002. Perilaku konsumen, Teori dan terapannya dalam pemasaran. Bandung (ID): PT. Ghalia Indonesia.

Tjiptono, F. 2004. Manajemen Jasa, Edisi Pertama. Yogyakarta (ID): Andi Offset.

Umar, H. 2010. Desain Penelitian Manajemen Strategik. Jakarta (ID): Grafindo Persada.

Utami, S. 2013. Pengaruh Bauran Pemasaran Terhadap Keputusan Pembelian Gula Pasir oleh Konsumen Rumah Tangga pada Pasar Swalayan di Kabupaten Karanganyar (Studi Kasus pada Konsumen merek Gulaku). [skripsi]. Surakarta (ID): Universitas Sebelas Maret.

Wells, L.E., Farley, H., \& Armstrong, G.A., 2007. The importance of packaging design for ownlabel food brands. International Journal of Retail \& Distribution Management, Vol. 35 (9): 677-690.

Wahab, A. 2012. Pengantar Ekonomi Makro. Makassar (ID): Alauddin University Press. 